Market performance implications of the transfer price rule

Stephen Martin and Jan Vandekerckhove

DEPARTMENT OF MANAGERIAL ECONOMICS, STRATEGY AND INNOVATION (MSI) 


\title{
Market Performance Implications of the Transfer Price Rule*
}

\author{
Stephen Martin ${ }^{\dagger}$ \\ Purdue University \\ Jan Vandekerckhove \\ Katholieke Universiteit Leuven
}

August 2010

\begin{abstract}
We model the impact of the transfer price rule (a constraint that requires the downstream division of a vertically-integrated firm to earn at least a normal rate of return on investment in the counterfactual case that it pays the same price as a nonintegrated firm for the essential input), rejected by the U.S. Supreme Court in Linkline, for the performance of markets in which an upstream firm provides an essential input to a downstream firm with which it may compete in the retail market by vertical integration. We allow for horizontal and vertical product differentiation in the final good market. The upstream firm's equilibrium distribution choice (between exclusion, dual distribution, or nonintegration) depends on relative product qualities. We characterize conditions under which the transfer price rule alters the upstream firm's equilibrium distribution choice, and develop conditions for the transfer price rule to improve market performance.

JEL codes: L12, L41, L44

Keywords: price squeeze; transfer price rule; vertical relations; antitrust

${ }^{*}$ We thank seminar participants at the Katholieke Universiteit Leuven, at Purdue University, at TU Dortmund, at the 2010 meetings of the Western Economic Association International, and Özlem Bedre-Defolie for useful comments. Responsibility for errors is our

${ }^{\dagger}$ Corresponding author.
\end{abstract} own. 


\section{Introduction}

The question of the appropriate antitrust treatment of a vertical price squeeze (Hovenkamp and Hovenkamp, 2009, p. 273),

... when a vertically integrated firm "squeezes" a rival's margins between a high wholesale price for an essential input sold to the rival and a low output price to consumers for whom the two firms compete,

is a hoary one, ${ }^{1}$ central to recent U.S. antitrust ${ }^{2}$ and EU competition policy ${ }^{3}$ cases. Many of these cases arise out of the interaction between downstream firms that supply internet access to final consumers, using as an essential input the upstream telecommunications infrastructure of vertically-integrated firms with which they compete in the downstream market.

The U.S. Linkline ${ }^{4}$ decision involved just such vertical relationships, between four California internet service providers (ISPs) of retail DSL (digital subscriber line) internet access, using wholesale transmission services purchased from Pacific Bell Telephone Co. (later, and in what follows, AT\&T), which itself provided retail DSL internet access. ${ }^{5}$

In July, 2003, the ISPs filed a private antitrust suit alleging that AT\&T had monopolized and attempted to monopolize the regional DSL market in violation of Section 2 of the Sherman Act (503 F. 3d 876 at 878), among other things by "creat[ing] a price squeeze by charging ISP a high wholesale price in relation to the price at which defendants were providing retail services."

AT\&T sought dismissal in District Court on the ground that since it had no obligation under the antitrust laws to deal with the ISPs at all, it could not have monopolized in violation of the Sherman Act if its prices did not permit them a normal rate of return on investment. The District Court did not accept this argument, the Ninth Circuit Court of Appeals refused to reverse the District Court, and AT\&T appealed to the Supreme Court.

In the resulting decision, the Supreme Court declined to treat "price squeeze" as a distinct business strategy for antitrust purposes, instead decomposing it

\footnotetext{
${ }^{1}$ Early U.S. antitrust decisions in which price squeezes were at issue include U.S. $v$. Corn Products Refining Co. et al. 234 F. 964 (1916) and U.S. v. Aluminum Co. of America et al. 148 F.2d 416 (2d Cir. 1945); on the latter, see Sidak (2008, p. 283, pp. 303-304) and Hovenkamp and Hovenkamp (2009).

${ }^{2}$ Among which, ARCO (Atlantic Richfield Co. v. USA Petroleum Co., 495 U.S. 328 (1990)) and Weyerhaeuser (Weyerhaeuser Co. v. Ross-Simmons Hardwood Lumber Co., Inc. 549 U. S. 312 (2007)). Sidak (2008, Section II.A) reviews U.S. price-squeeze decisions arising in the telecommunications sector.

${ }^{3}$ For example, Telefónica (Case COMP/38.784 - Wanadoo España v. Telefónica Commission Decision of 4 July 2007) and Wanadoo (France Télécom SA $v$ Commission Case C-202/07 2 April 2009). See Crocioni and Veljanovski (2003), Bravo and Siciliani (2007) for discussions.

${ }^{4}$ Pacific Bell Telephone Co. et al. v. Linkline Communications, Inc., et al. 555 U. S. (2009).

${ }^{5}$ The Linkline decisions treated DSL internet access as the relevant product market. At this time and in this geographic market, DSL, dial-up, and cable modem were alternatives available to final consumers. The outcomes of these decisions did not, however, turn on the question of product market definition.
} 
into two parts, each of which could be treated according to existing antitrust standards. First, the high wholesale price that is the lower prong of a price squeeze is an exercise of monopoly power, which for antitrust economics is the ability to control price or exclude competition. The exercise of lawfully obtained market power does not offend U.S. antitrust law (in particular, the Sherman Act Section 2 prohibition of monopolization). ${ }^{6}$ Second, the low retail price that is the upper prong of a price squeeze is monopolization if it is predatory, otherwise not. $^{7}$

Along the way to sending the case back to District Court for further proceedings consistent with its guidance, the Supreme Court took the opportunity to reject application of the "transfer price rule" approach to vertical price squeezes, an approach suggested by the American Antitrust Institute in a friend-of-thecourt brief. ${ }^{8}$ The transfer price test would find monopolization if $(555 \mathrm{U}$. S. 14)

the upstream monopolist could not have made a profit by selling at its retail rates if it purchased inputs at its own wholesale rates.

When it rejected use of the transfer price test, the Supreme Court did so without analysis of its impact on retail market performance, simply stating (555 U. S. $14):^{9}$

Whether or not that test is administrable, it lacks any grounding in our antitrust jurisprudence. An upstream monopolist with no duty to deal is free to charge whatever wholesale price it would like; antitrust law does not forbid lawfully obtained monopolies from charging monopoly prices.

\footnotetext{
${ }^{6}$ It is otherwise for EU competition policy: under Article 102 of the EU Treaty, the mere exercise of market power is in principle an abuse of a dominant position.

${ }^{7}$ Under, inter alia, Brooke Group, a price is predatory if it is below an appropriate measure of unit cost and if the firm charging the price would have an objectively reasonable expectation of recouping profits lost while setting a predatory price. EU competition policy takes demonstration of a price below unit cost as establishing that a firm expected to be able to recoup predatory losses; no separate demonstration of recoupment is required to find that a price below unit cost abuses a dominant position (Tetra Pak II (Case C-333/94 P Tetra Pak International SA $v$. Commission 1996 ECR I-5951) \ 44, Wanadoo.)

${ }^{8}$ One author of this paper is a member of the Advisory Board of the American Antitrust Institute. He was not involved in any way in preparation of the aforementioned brief.

${ }^{9}$ The European Commission has applied the transfer price rule, although not by that name. See Motta and de Streel's (2006, pp. 118-120) discussion of British Sugar (Commission Decision of 18 July 1988, Napier Brown-British Sugar, OJ L 284 [1988]; quoting 96 of the Commission decision, "A company which is dominant in the market for both a raw material and a corresponding derived product may not maintain a margin between both prices which is insufficient to reflect that dominant company's own costs of transformation with the result that competition in the derived product is restricted") and Deutsche Telekom (Commission Decision of 21 May 2003, Deutsche Telekom, OJ L 263 [2003], quoting 107 of the Commission decision, "there is an abusive margin squeeze if the difference between the retail prices charged by the dominant undertaking and the wholesale prices it charges its competitors for comparable services is negative, or insufficient to cover the product-specific costs to the dominant operator of providing its own retail services on the downstream market").
} 
Our goal in this paper is to model the equilibrium choice of distribution arrangement by an upstream, and possibly vertically integrated, firm, the resulting market performance, and to model the impact of the transfer price rule on the choice of distribution mode and on market performance.

We outline our basic analytical framework in Section 2. In Section 3 we analyze the upstream firm's equilibrium choice of distribution mode if it is not subject to the transfer price rule. In Section 4, we discuss the implications of the transfer price rule for the upstream firm's equilibrium choice of distribution mode and for market performance. Section 5 concludes. Details of results are given in the Appendix; derivations are available from the authors on request.

\section{Setup}

We model a vertically-structured market in which one firm, firm A, is the monopoly supplier of an essential input for production of a final good. We suppose that one unit of the essential input is required to produce one unit of the final product, and that the essential input is produced at constant marginal cost, which, for simplicity, we normalize to be zero. We further assume that the downstream market is supplied by at most one nonintegrated firm. Vertical price squeezes have been an issue in cases where the downstream market is a small-numbers oligopoly. By focusing on the limiting case of one downstream firm, we avoid highlighting horizontal relationships among downstream firms at the expense of the vertical relationships in which we wish to focus. ${ }^{10}$

\subsection{Sequence}

There are at most three stages in the market (Figure 1). In stage I, firm A chooses one of three distribution modes (Figure 2). It may choose to fully internalize distribution, refusing to supply the downstream firm with the essential input and so excluding the downstream firm, firm B, from the final good market. It may choose dual distribution, integrating downstream and competing with firm $B$, to which it supplies the essential input at wholesale price $\omega \rho_{B}$ (where $\rho_{B}$ is a demand parameter and a measure of product quality). The third distribution mode is nonintegration: firm A operates only upstream, and supplies final demand using the distribution services of firm B, which again purchases the essential input at wholesale price $\omega \rho_{B}$ and is the monopoly supplier to the final good market.

In stage II, which occurs only if firm A opts for dual distribution or nonintegration, firm A sets wholesale price $\omega \rho_{B} \cdot{ }^{11}$ We assume that firm B enters the

\footnotetext{
${ }^{10}$ Carlton (2008) discusses (without formally presenting) a similar model. By allowing at most one independent downstream firm, we also rule out "hold up" effects in vertical relationships of the kind considered by Hart and Tirole (1990).

${ }^{11}$ We treat constructive refusal, in which firm A announces that it will supply the essential input to firm B at a price that makes it uneconomic for firm B to purchase the essential input, as a form of exclusion. Thus if firm A opts for duopoly distribution, it sets a wholesale price that maximizes firm A's value, assuming that firm B earns at least a normal rate of return on
} 
Firm A selects distribution mode
If nonintegration or dual distribution, firm A selects $\omega$
Active firms set prices

Figure 1: Sequence of decisions.

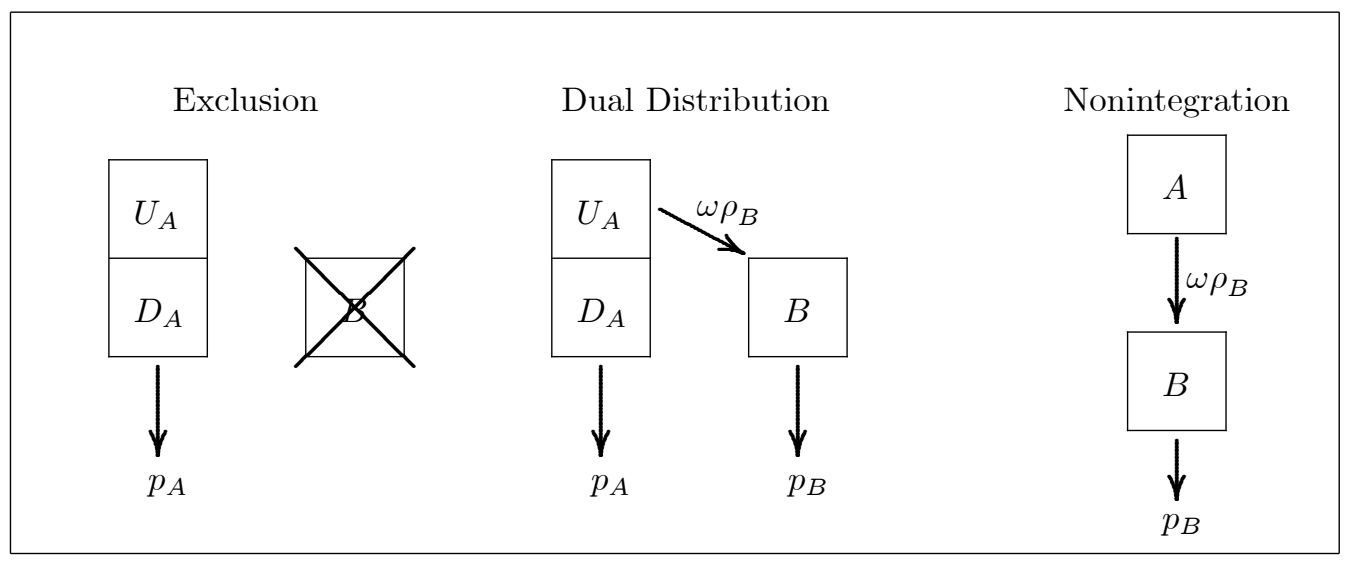

Figure 2: Alternative distribution modes.

downstream market if entry will allow it to earn at least a normal rate of return on investment.

Finally, in stage III, firms that are active in the downstream market set prices to maximize own present-discounted value over all future time. If there is dual distribution, prices are set non-cooperatively. The game is solved backward.

\subsection{Demand}

If firms A and B supply the downstream market, they do so with horizontallyand vertically-differentiated varieties. We model downstream demand with the Spence-Dixit-Vives linear demand specification. The inverse demand equation investment. 
for variety $i$ is ${ }^{12,13}$

$$
p_{i}=\rho_{i}-\frac{1}{N}\left(\rho_{i} q_{i}+\sigma \sqrt{\rho_{A} \rho_{B}} q_{j}\right) .
$$

Here $\rho_{i}$ is the maximum reservation price for variety $i$, which we interpret as a measure of quality. Equation (2) thus allows for vertical product differentiation. This specification can be derived from a discrete choice model in which each of $N$ consumers, uniformly distributed by reservation price from 0 to $\rho_{i}$, purchases one unit of a variety if its price is less than the consumer's reservation price (Martin, 2009). In this model, $N$ is a measure of market size. $\sigma$, which lies between zero and one, measures horizontal substitutability between the two varieties.

In what follows, we work with the demand equations implied by (2),

$$
q_{A}=\frac{N}{1-\sigma^{2}}\left(1-R \sigma-\frac{p_{A}}{\rho_{A}}+\sigma R \frac{p_{B}}{\rho_{B}}\right)
$$

for firm $\mathrm{A}$ and

$$
q_{B}=\frac{N}{1-\sigma^{2}}\left(1-\frac{\sigma}{R}-\frac{p_{B}}{\rho_{B}}+\frac{\sigma}{R} \frac{p_{A}}{\rho_{A}}\right) .
$$

for firm B, where

$$
R=\sqrt{\frac{\rho_{B}}{\rho_{A}}}
$$

is a measure of relative product quality and indicates the extent of vertical product differentiation.

\subsection{Cost}

If firm $i$ enters the downstream market, it incurs a completely sunk entry cost $E_{i}(i=A, B)$ and a fixed cost $F_{i}$ per unit time period. It also incurs a constant marginal cost per unit of output for all inputs other than the essential input produced by firm A. To highlight the impact of vertical input pricing, and for notational simplicity, we normalize marginal cost to be zero.

\section{Alternative Distribution Regimes}

We first consider firm A's equilibrium choice of distribution mode, and resulting market performance, if the transfer price rule is not in place.

\footnotetext{
${ }^{12}$ Henceforth, let it be understood that the subscripts $i, j$ refer to $i, j=A, B$ and $i \neq j$.

${ }^{13}$ Inverse demand equations of this form can be derived from a quadratic social welfare function

$$
U=H+\rho_{A} q_{A}+\rho_{B} q_{B}-\frac{1}{2} \frac{1}{N}\left(\rho_{A} q_{A}^{2}+2 \sigma \sqrt{\rho_{A} \rho_{B}} q_{A} q_{B}+\rho_{B} q_{B}^{2}\right)
$$

where $N$, the number of consumers, is a market size parameter, and $H$ is a Hicksian numeraire good produced at unit cost under constant returns to scale.
} 


\begin{tabular}{|l|l|l|}
\hline & Exclusion & Nonintegration \\
\hline$\omega$ & NA & $\frac{1}{2}$ \\
\hline$q_{A}$ & $\frac{1}{2} N$ & $\mathrm{NA}$ \\
\hline$q_{B}$ & $\mathrm{NA}$ & $\frac{1}{4} N$ \\
\hline$p$ & $\frac{1}{2} \rho_{A}$ & $\frac{3}{4} \rho_{B}$ \\
\hline$\frac{r}{N} V_{A}$ & $\frac{1}{4} \rho_{A}-k_{A}$ & $\frac{1}{8} \rho_{B}$ \\
\hline$\frac{r}{N} V_{B}$ & $\mathrm{NA}$ & $\frac{1}{16} \rho_{B}-k_{B}$ \\
\hline$\frac{r}{N} C S$ & $\frac{1}{8} \rho_{A}$ & $\frac{1}{32} \rho_{B}$ \\
\hline$\frac{r}{N} N S W$ & $\frac{3}{8} \rho_{A}-k_{A}$ & $\frac{7}{32} \rho_{B}-k_{B}$ \\
\hline
\end{tabular}

Table 1: Exclusion and nonintegration outcomes.

\subsection{Exclusion}

If firm A internalizes the distribution function, it sets price to maximize its present discounted value,

$$
V_{A}^{e x}=\frac{\left(\rho_{A}-\frac{\rho_{A}}{N} q_{A}^{e x}\right) q_{A}^{e x}-\left(F_{A}+r E_{A}\right)}{r},
$$

where interest rate $r$ is used to discount future income.

With firm A the single supplier of the downstream market, the demand equation is

$$
q_{A}^{e x}=N\left(\frac{\rho_{A}-p_{A}^{e x}}{\rho_{A}}\right) .
$$

Firm A's value-maximizing output, price, and value are given in Table 1, column 2 , along with equilibrium consumer surplus $(C S)$ and net social welfare $(N S W$, the sum of firm value and consumer surplus).

Note from Table 1 that firm A's exclusion value satisfies

$$
\frac{r}{N} \frac{V_{A}^{e x}}{\rho_{A}}=\frac{1}{4}-\frac{k_{A}}{\rho_{A}},
$$

where we write

$$
k_{i}=\frac{F_{i}+r E_{i}}{N}
$$

for firm $i$ 's fixed and capitalized sunk entry cost relative to market size. If $k_{A} \geq$ $\frac{1}{4} \rho_{A}$, firm A would never exclude firm B. So as not to rule out exclusion by assumption, in what follows we assume

$$
\frac{k_{A}}{\rho_{A}}<\frac{1}{4} .
$$

\subsection{Nonintegration}

If firm A operates only at the upstream level, firm B supplies the downstream market and sets $p_{B}$ to maximize

$$
V_{B}^{n i}=\frac{\left(\rho_{B}-\omega \rho_{B}-\frac{\rho_{B}}{N} q_{B}^{n i}\right) q_{B}^{n i}-\left(F_{A}+r E_{A}\right)}{r},
$$


with

$$
q_{B}^{n i}=N\left(\frac{\rho_{B}-p_{B}^{n i}}{\rho_{B}}\right)
$$

denoting the quantity demanded when firm B is the only supplier.

In stage II, firm A sets the wholesale price $\omega$ to maximize

$$
V_{A}^{n i}=\frac{1}{r} \omega \rho_{B} q_{B}^{n i}(\omega) .
$$

The resulting wholesale price and other equilibrium characteristics are given in Table 1, column 3 .

\subsection{Dual distribution}

\subsubsection{Stage III: Retail Prices}

With dual distribution, firms $\mathrm{A}$ and $\mathrm{B}$ compete as price-setting duopolists in stage III, the wholesale price $\omega$ having been set by firm A in stage II. Firm A's objective function is the present value of the sum of its profit from sales of the final good and its profit from sales to firm B of the essential input,

$$
V_{A}^{d d 3}=\frac{1}{r}\left[p_{A} q_{A}\left(p_{A}, p_{B}\right)-F_{A}-r E_{A}+\omega q_{B}\left(p_{A}, p_{B}\right)\right],
$$

where $q_{A}\left(p_{A}, p_{B}\right)$ and $q_{B}\left(p_{A}, p_{B}\right)$ are the demand equations (3) and (4).

Firm B's objective function is the present value of profit from its sales of the final good,

$$
V_{B}^{d d 3}=\frac{1}{r}\left[\left(p_{B}-\omega \rho_{B}\right) q_{B}^{d d 3}\left(p_{A}, p_{B}\right)-\left(F_{B}+r E_{B}\right)\right] .
$$

Stage III noncooperative equilibrium prices as functions of $\omega$, along with the corresponding quantities demanded, are given in the Appendix.

\subsubsection{Stage II: Wholesale Price}

In stage II, firm A picks $\omega$ to solve

$$
\max _{\omega} V_{A}^{d d 2}=\frac{1}{r}\left[p_{A}(\omega) q_{A}^{d d 2}(\omega)-\left(F_{A}+r E_{A}\right)+\omega q_{B}^{d d 2}(\omega)\right] .
$$

Two cases need to be considered, depending on whether the value of $\omega$ that maximizes firm A's value does or does not leave firm B with nonnegative value. We first consider the case in which the solution to (16) implies that firm B's dual-distribution participation constraint, $V_{B}^{d d 2} \geq 0$, is satisfied.

The value-maximizing wholesale price is

$$
\omega^{d d}=\frac{1}{2} \frac{1}{8+\sigma^{2}}\left(8+\frac{\sigma^{3}}{R}\right)
$$


and falls as $R$ rises. Thus, the greater is the relative quality of the nonintegrated firm's variety, the more it is in firm A's interest to increase the quantity demanded of the nonintegrated firm, thereby raising derived demand for the essential input.

Equilibrium outputs are

$$
q_{A}^{d d}=N \frac{3 \sigma}{\left(1-\sigma^{2}\right)\left(8+\sigma^{2}\right)}\left[\frac{\left(1-\sigma^{2}\right)\left(\sigma^{2}+8\right)}{6 \sigma}+\sigma-R\right]
$$

and

$$
q_{B}^{d d}=\frac{N}{1-\sigma^{2}} \frac{2+\sigma^{2}}{8+\sigma^{2}}\left(\frac{R-\sigma}{R}\right) .
$$

Firm A's duopoly output, (18), decreases as $R$ rises, reaching zero for

$$
R_{A Z}=\sigma+\frac{\left(1-\sigma^{2}\right)\left(8+\sigma^{2}\right)}{6 \sigma} .
$$

From (19) it follows that $R>\sigma$ is a condition for firm $\mathrm{B}$ to have positive duopoly output.

Firm A's equilibrium value, $V_{A}^{d d}$, satisfies

$$
\frac{r}{N} V_{A}^{d d}=\frac{1}{4} \rho_{A}+\frac{1}{1-\sigma^{2}} \frac{\rho_{A}}{\left(8+\sigma^{2}\right)}(R-\sigma)^{2}-k_{A}
$$

(21) can be rewritten in two ways that are useful.

First,

$$
\frac{r}{N} \frac{V_{A}^{d d}}{\rho_{A}}=\frac{1}{4}+\frac{1}{N^{2}} \frac{\left(1-\sigma^{2}\right)\left(8+\sigma^{2}\right)}{\left(2+\sigma^{2}\right)^{2}} R^{2}\left(q_{B}^{d d}\right)^{2}-\frac{k_{A}}{\rho_{A}} .
$$

Thus firm A's value rises as firm B's equilibrium output rises, and rises more rapidly, the greater is the relative quality of firm B's variety, $R$. On the one hand, $\omega^{*}$ and firm A's own output both fall as $R$ rises (see (17) and (18)). On the other hand, however, firm B's output rises as $R$ rises (see (19)), and firm A sells one unit of the essential input to firm B for every unit of output that firm B sells. (21) shows that the latter effect more than outweighs the first two.

Alternatively, firm A's duopoly value satisfies

$$
\frac{V_{A}^{d d}-V_{A}^{e x}}{\rho_{A}}=\frac{1}{r} \frac{1}{N} \frac{\left(1-\sigma^{2}\right)\left(8+\sigma^{2}\right)}{\left(2+\sigma^{2}\right)^{2}} R^{2}\left(q_{B}^{d d}\right)^{2} \geq 0 .
$$

From (23), firm A's duopoly value exceeds its exclusion value if firm B has positive duopoly output.

Firm B's equilibrium dual-distribution value satisfies

$$
\frac{r}{N} V_{B}^{d d}=\frac{1}{1-\sigma^{2}}\left(\frac{2+\sigma^{2}}{8+\sigma^{2}}\right)^{2} \rho_{A}(R-\sigma)^{2}-k_{B} .
$$


Although firm B has positive duopoly output for $R>\sigma$, its duopoly value is nonnegative only if $R$ takes the larger value

$$
R \geq \sigma+\frac{8+\sigma^{2}}{2+\sigma^{2}} x \equiv R_{B},
$$

where we write

$$
x=\sqrt{\left(1-\sigma^{2}\right) \frac{k_{B}}{\rho_{A}}}
$$

for notational compactness.

By (19) and (23), for $\sigma \leq R<R_{B}$, firm A's dual distribution value would exceed its exclusion value, but firm $\mathrm{B}$ would not accept to distribute its variety of the product at the wholesale price $\omega^{d d}$ (equation (17)).

We can show that for values of $R$ in the range $R_{1} \leq R \leq R_{B}$, where

$$
R_{1}=\sigma+\frac{1}{\sigma^{2}}\left(2+\sigma^{2}-2 \sqrt{1-\sigma^{2}}\right) x,
$$

firm A enjoys greater value, compared with exclusion, by lowering $\omega$ enough to allow firm B to break even under dual distribution. We refer to this regime as constrained dual distribution ( $c d d) . R_{1}$ is the value of $R$ at which firm A's constrained dual-distribution value equals its exclusion value.

The appropriate formulation of firm A's constrained value-maximization problem is

$$
\max _{\omega} V_{A}^{d d 2} \text { s.t. } V_{B}^{d d 2} \geq 0 .
$$

For $R$ in this range, firm B's participation constraint is binding, yielding the wholesale price

$$
\omega^{c d d}=\frac{1}{2}\left[\frac{2-\sigma^{2}-\frac{\sigma}{R}}{1-\sigma^{2}}-\frac{1}{R} \frac{4-\sigma^{2}}{1-\sigma^{2}} x\right],
$$

which is, as expected, smaller than $\omega^{d d}$. If firm B's participation constraint is binding, firm A's constrained dual distribution value satisfies

$$
\frac{r}{N} \frac{V_{A}^{c d d}}{\rho_{A}}=\frac{r}{N} \frac{V_{A}^{e x}}{\rho_{A}}+\frac{1}{4} \frac{\sigma^{2}}{\left(1-\sigma^{2}\right)^{2}}\left[4 x^{2} \frac{1-\sigma^{2}}{\sigma^{4}}-\left(R-\sigma-\frac{2+\sigma^{2}}{\sigma^{2}} x\right)^{2}\right] .
$$

\subsection{Equilibrium Choice of Distribution Mode}

Firm A's dual distribution value satisfies (21). From Table 1, its nonintegration value satisfies

$$
\frac{r}{N} V_{A}^{n i}=\frac{1}{8} \rho_{B}=\frac{1}{8} \rho_{A} R^{2} .
$$

If firm B's participation constraint is not binding, so that (16) is firm A's value-maximization problem, the difference between firm A's unconstrained dual-distribution value and its nonintegration value satisfies

$$
8 \frac{\left(1-\sigma^{2}\right)\left(8+\sigma^{2}\right)}{7+\sigma^{2}} \frac{r}{N} \frac{V_{A}^{d d}-V_{A}^{n i}}{\rho_{A}}=
$$




$$
\left(R \sigma-\frac{8}{7+\sigma^{2}}\right)^{2}+8 \frac{\left(1-\sigma^{2}\right)\left(8+\sigma^{2}\right)}{7+\sigma^{2}}\left(\frac{1}{4} \frac{3+\sigma^{2}}{7+\sigma^{2}}-\frac{k_{A}}{\rho_{A}}\right) .
$$

We have assumed $\frac{k_{A}}{\rho_{A}}<\frac{1}{4}$ (see (10)). For notational compactness, write

$$
R_{L}=\sigma+\frac{1}{\sigma}\left[\frac{\left(1-\sigma^{2}\right)\left(8+\sigma^{2}\right)}{7+\sigma^{2}}-\sqrt{8 \frac{\left(1-\sigma^{2}\right)\left(8+\sigma^{2}\right)}{7+\sigma^{2}}\left(\frac{k_{A}}{\rho_{A}}-\frac{13+\sigma^{2}}{4} \frac{3+\sigma^{2}}{7}\right)}\right]
$$

and

$$
R_{H}=\sigma+\frac{1}{\sigma}\left[\frac{\left(1-\sigma^{2}\right)\left(8+\sigma^{2}\right)}{7+\sigma^{2}}+\sqrt{8 \frac{\left(1-\sigma^{2}\right)\left(8+\sigma^{2}\right)}{7+\sigma^{2}}\left(\frac{k_{A}}{\rho_{A}}-\frac{1}{4} \frac{3+\sigma^{2}}{7+\sigma^{2}}\right)}\right] .
$$

$R_{L}$ and $R_{H}$ are the two values of $R$ at which $V_{A}^{d d}=V_{A}^{n i}$ (that is, they are the values of $R$ for which the right-hand side of (32) equals zero). It can be shown that $R_{1}<R_{B}$ and $R_{L}<R_{A Z}$.

The relation between relative quality $R$ and firm A's value-maximizing distribution choice is of one of three types, depending on the magnitude of $k_{A} / \rho_{A}$. The cases are summarized in Theorem 1.

Theorem 1L: low $\frac{k_{A}}{\rho_{A}}$ : for

$$
\frac{k_{A}}{\rho_{A}} \leq \frac{1}{4} \frac{3+\sigma^{2}}{7+\sigma^{2}}
$$

firm A's value-maximizing distribution choices are

- $0 \leq R<R_{1}$ : exclusion;

- $R_{1} \leq R \leq R_{B}$ : dual distribution, firm B's participation constraint binding;

- $R_{B} \leq R<R_{A Z}$ : unconstrained dual distribution;

- $R \geq R_{A Z}$ : nonintegration.

Theorem 1M: intermediate $\frac{k_{A}}{\rho_{A}}$ : for

$$
\frac{1}{4} \frac{3+\sigma^{2}}{7+\sigma^{2}}<\frac{k_{A}}{\rho_{A}}<\frac{1}{4} \frac{3+\sigma^{2}}{7+\sigma^{2}}+\frac{1}{288} \frac{\left(1-\sigma^{2}\right)\left(1+\sigma^{2}\right)^{2}\left(8+\sigma^{2}\right)}{7+\sigma^{2}}
$$

firm A's value-maximizing distribution choices are

- $0 \leq R<R_{1}$ : exclusion;

- $R_{1} \leq R \leq R_{B}$ : dual distribution, firm B's participation constraint binding; 
- $R_{B} \leq R<R_{L}$ : unconstrained dual distribution;

- $R_{L} \leq R<R_{H}$ : nonintegration;

- $R_{H} \leq R<R_{A Z}$ : unconstrained dual distribution;

- $R \geq R_{A Z}$ : nonintegration.

Theorem 1H: high : $\frac{k_{A}}{\rho_{A}}$ : for

$$
\frac{1}{4} \frac{3+\sigma^{2}}{7+\sigma^{2}}+\frac{1}{288} \frac{\left(1-\sigma^{2}\right)\left(1+\sigma^{2}\right)^{2}\left(8+\sigma^{2}\right)}{7+\sigma^{2}} \leq \frac{k_{A}}{\rho_{A}} \leq \frac{1}{4}
$$

firm A's value-maximizing distribution choices are

- $0 \leq R<R_{1}$ : exclusion;

- $R_{1} \leq R \leq R_{B}$ : dual distribution, firm B's participation constraint binding;

- $R_{B} \leq R<R_{L}$ : unconstrained dual distribution;

- $R_{L} \leq R_{A Z}$ : nonintegration.

If $R_{B} \geq R_{A Z}$ for the low $k_{A} / \rho_{A}$ case, or $R_{B} \geq R_{L}$ for the high $k_{A} / \rho_{A}$ case, once again dual distribution does not occur: firm A's optimal strategy passes directly from exclusion to nonintegration at the value $R=R_{X N}$ at which firm A's exclusion value equals its nonintegration value. These cases may occur for $\sigma$ sufficiently close to 1 . Theorem 1 holds for $\sigma$ in the range where firm 1 will opt for dual distribution for some values of $R .{ }^{14}$ In Figure 4 we illustrate firm A's choice of distribution mode for all $\sigma$.

Theorem 1L is illustrated in Figure 3, for an intermediate value of $\sigma$. For low values of $k_{A} / \rho_{A}$, firm $\mathrm{A}$ maximizes its value by excluding firm $\mathrm{B}$ for $0 \leq R<R_{1}$. For $R_{1} \leq R \leq R_{B}$, firm $\mathrm{A}$ maximizes value by setting its wholesale price $\omega$ so that firm B just breaks even under dual distribution. ${ }^{15}$ For $R$ between $R_{B}$ and $R_{A Z}$, firm $\mathrm{A}$ maximizes its value by pricing the essential input at its unconstrained value, thereby allowing firm $\mathrm{B}$ to realize positive value. For $R=R_{A Z}$, A's dual-distribution output is zero; firm A distributes solely through firm $\mathrm{B}$ for $R \geq R_{A Z}$.

Note that there is a discontinuous drop in firm A's value when it switches from dual distribution to nonintegration. For $R$ sufficiently close to $R_{A Z}$, the value of firm A's downstream operation, artificially considered as a stand-alone

\footnotetext{
${ }^{14}$ For $\sigma$ near 1, it may also happen (as illustrated in Figure 4) that as $R$ rises from low levels, firm A's optimal distribution choice passes from exclusion to constrained dual distribution to dual distribution, back to exclusion, and then to nonintegration. Theorem 1 holds for values of $\sigma$ below this range.

${ }^{15}$ We make a "tie-breaking" assumption that if firm B earns a normal rate of return on investment, it accepts to distribute the final good.
} 


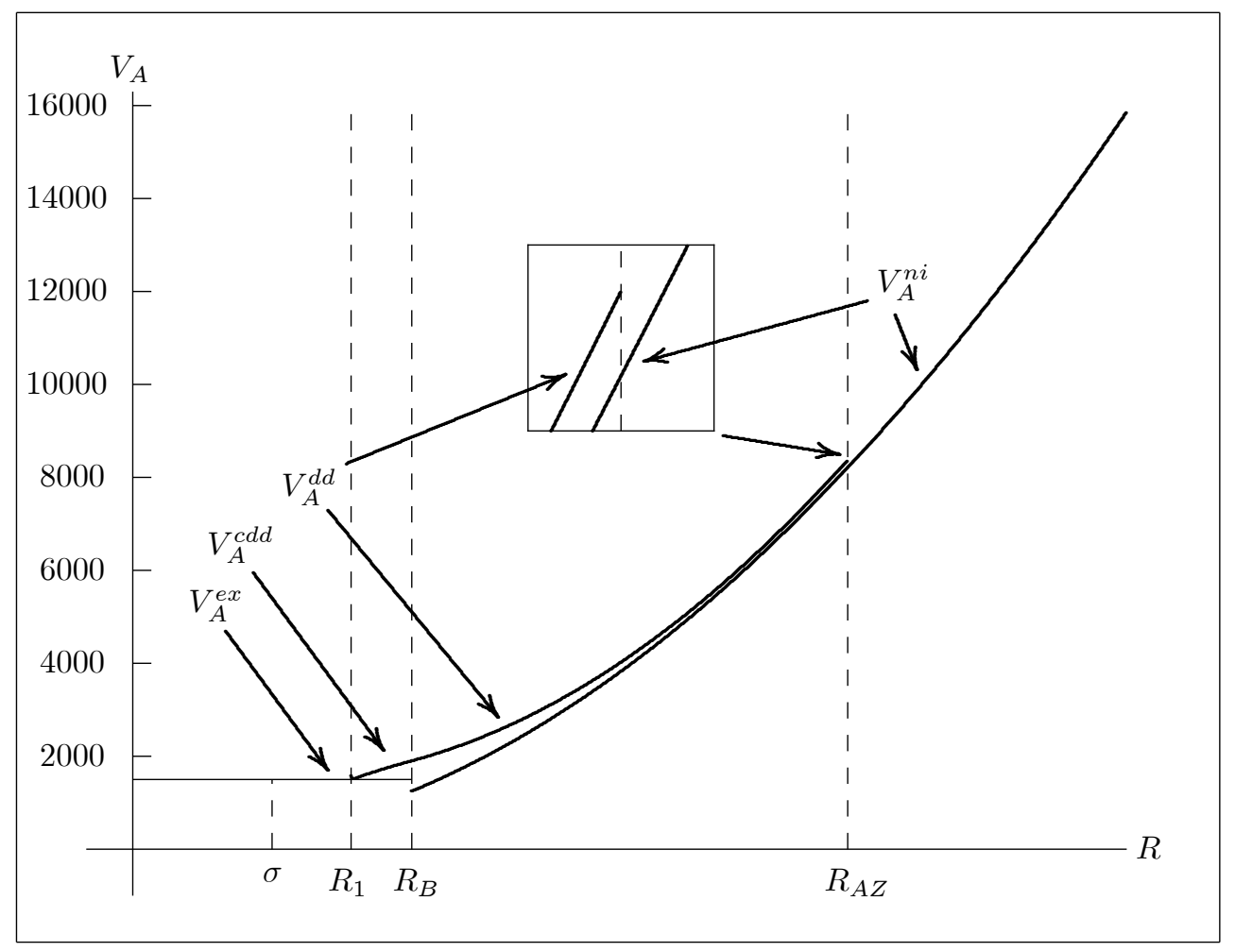

Figure 3: Low $k_{A} / \rho_{A} ; \sigma=\frac{1}{2}, N=1000, r=1 / 10 ; R=\sqrt{\rho_{B} / \rho_{A}}, V_{A}=$ firm A's value; superscripts ex, $c d d, d d, n i$ indicate exclusion, constrained dual distribution, dual distribution, and nonintegration, respectively.

activity, is negative. ${ }^{16}$ However, it is nonetheless value-maximizing for firm A to operate at the downstream level as long as its output is positive: the presence of firm A's variety on the downstream market limits the double-marginalization that affects firm B's output. ${ }^{17}$ At $R=R_{A Z}$, firm A's dual-distribution drops to zero. For higher values of $R$, the full double-marginalization effect kicks in, due to firm A's nonintegration, and there is a discontinuous decline in firm A's equilibrium value.

\footnotetext{
${ }^{16}$ That is, $\frac{r}{N} \frac{V_{A}^{d s}}{\rho_{A}}=\frac{p_{A}}{\rho_{A}} \frac{q_{A}}{N}-\frac{k_{A}}{\rho_{A}}<0$ for $R$ sufficiently close to $R_{A Z}$. This must be so, since $\frac{p_{A}}{\rho_{A}}$ approaches a positive value as $R \longrightarrow R_{A Z}$, while (by definition of $\left.R_{A Z}\right) \frac{q_{A}}{N} \longrightarrow 0$ as $R \stackrel{\rho_{A}}{\longrightarrow} R_{A Z}$.

${ }^{17}$ Discussing anticompetitive price squeezes - those that worsen market performance Motta and de Streel (2006, p. 115, footnote 59) discuss cross-subsidization of a retail division by the wholesale division of a vertically-integrated firm. In our model, for $R$ sufficiently close to $R_{A Z}$, cross-subsidization is not only privately profitable for the integrated firm but also improves market performance, by limiting double marginalization. Nor does cross-subsidization make the nonintegrated firm unprofitable; it makes the nonintegrated firm less profitable than would otherwise be the case, to the benefit of consumers.
} 


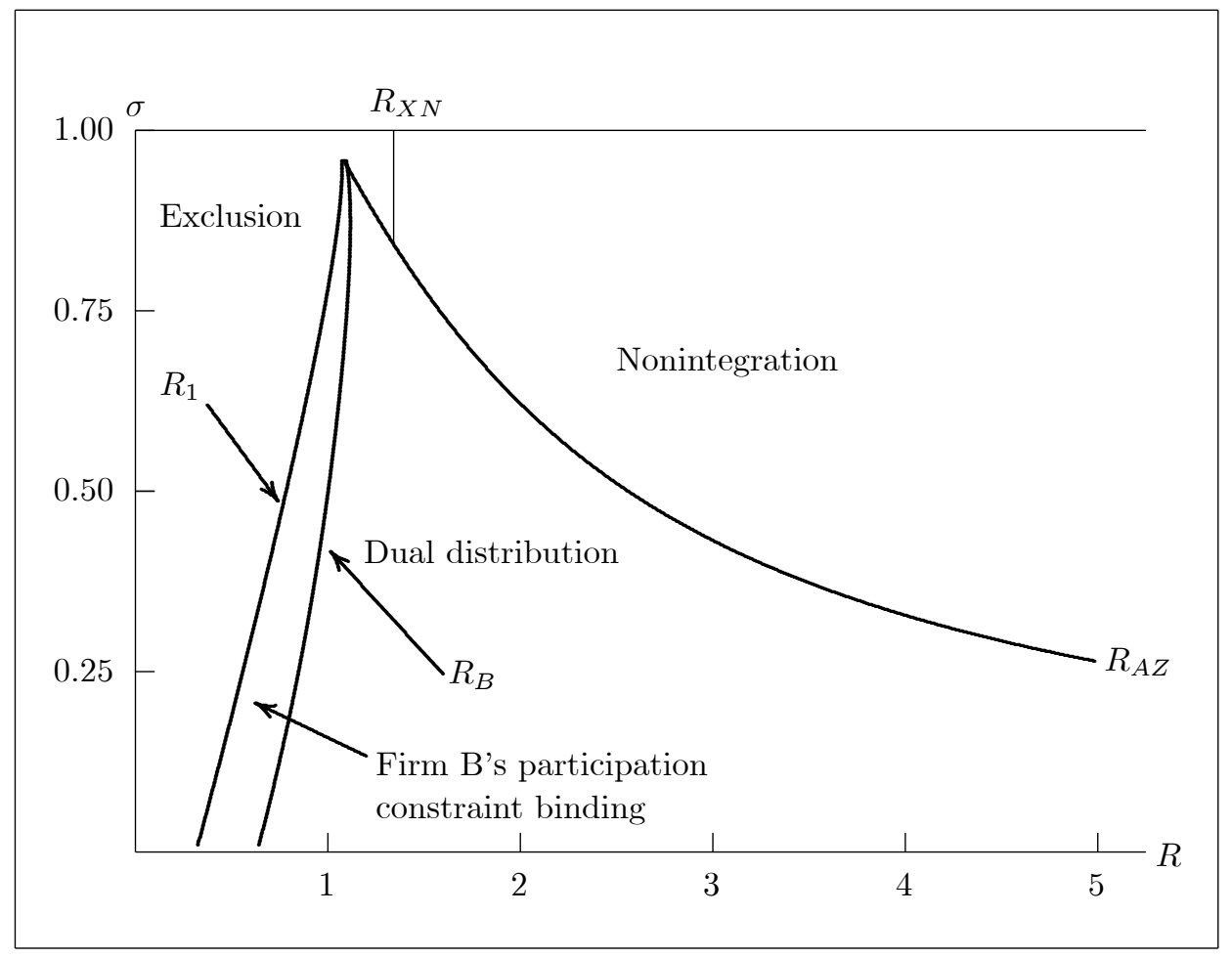

Figure 4: Firm A's choice of distribution mode, low $k_{A}$, low $k_{B}$, no transfer price rule.

Figure 4 shows firm A's value-maximizing choice of distribution mode in $(R, \sigma)$-space for the case of Theorem 1L. The range of values of $R$ consistent with dual distribution narrows as varieties become closer substitutes. As noted above, for $\sigma$ sufficiently close to 1 , dual distribution is never firm A's valuemaximizing choice.

Theorem $1 \mathrm{H}$ is illustrated in Figure 5. For high values of $k_{A} / \rho_{A}$, as for low, constrained dual distribution begins with $R=R_{1}$, and unconstrained dual distribution begins with $R=R_{B}$. As $R$ rises from $R_{B}$, dual distribution continues to be firm A's value-maximizing choice until $R$ reaches $R_{L}$, the smaller of two values at which $V_{A}^{d d}=V_{A}^{n i}$. As $R$ rises above $R_{L}, V_{A}^{d d}$ falls below $V_{A}^{n i}$, and for high values of $k_{A} / \rho_{A}, V_{A}^{d d}<V_{A}^{n i}$ for $R \geq R_{L}$. For high values of $k_{A} / \rho_{A}$, firm A opts out of dual distribution before its dual-distribution output goes to zero. ${ }^{18}$

The range of intermediate values of $k_{A} / \rho_{A}$, for which Theorem $1 \mathrm{M}$ applies,

\footnotetext{
${ }^{18}$ A figure (corresponding to Figure 4) illustrating firm A's value-maximizing choice of distribution mode in $(R, \sigma)$-space for the case of Theorem $1 \mathrm{H}$ is given in an Appendix that is available on request from the authors. The general configuration of the regions in $(R, \sigma)$-space is similar to that of $(R, \sigma)$-space.
} 


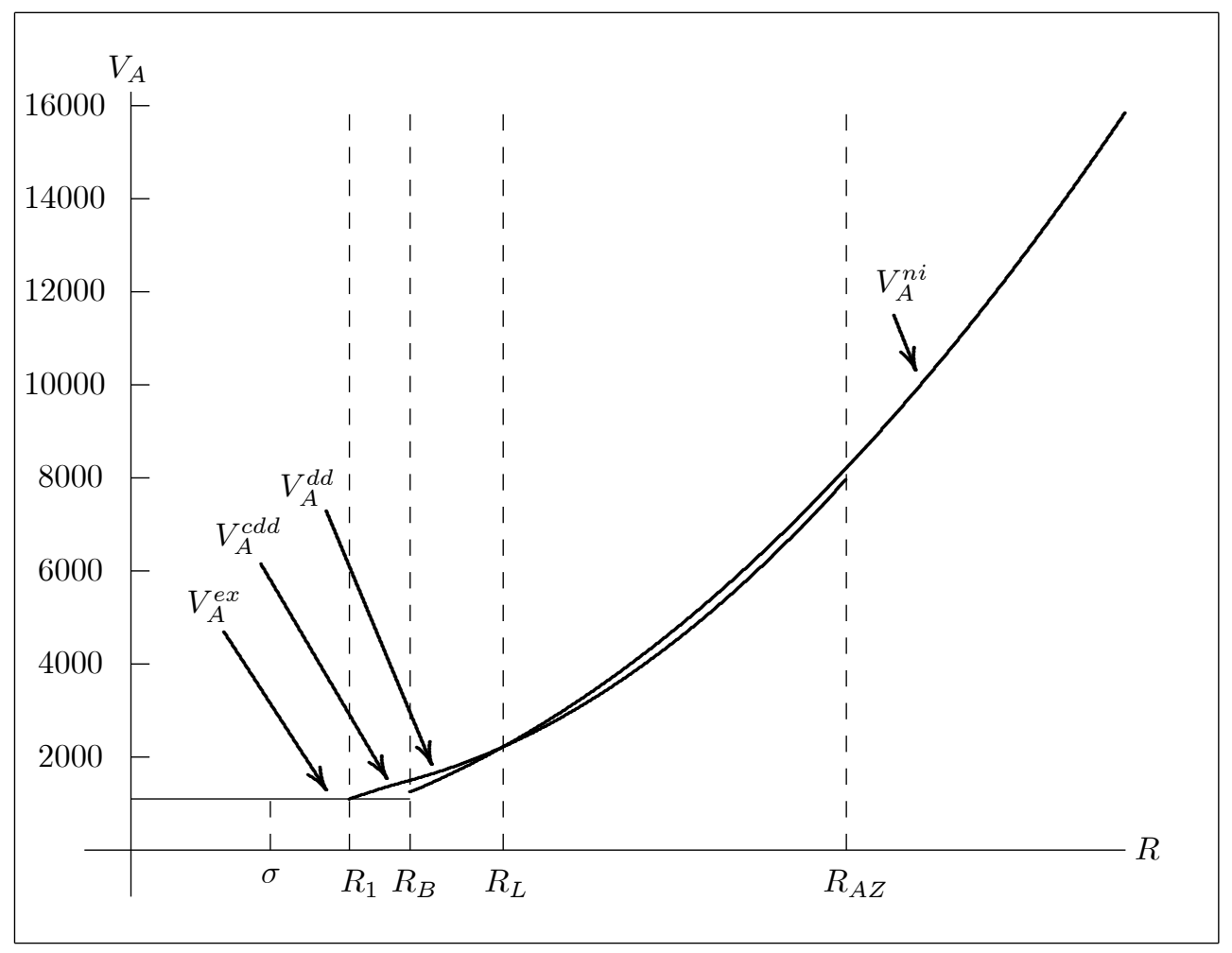

Figure 5: Case III: high $k_{A} / \rho_{A} ; \sigma=\frac{1}{2}, N=1000, r=1 / 10 ; R=\sqrt{\rho_{B} / \rho_{A}}$, $V_{A}=$ firm A's value; superscripts $e x, c d d, d d, n i$ indicate internalization, constrained dual distribution, dual distribution, and nonintegration, respectively.

is a narrow one. ${ }^{19}$ Theorem $1 \mathrm{M}$ has in common with Theorem $1 \mathrm{H}$ that firm $\mathrm{A}$ maximizes value by internalizing distribution for $0 \leq R<R_{1}$ and opts for dual distribution as $R$ rises above $R_{L}$. But for intermediate values of $k_{A} / \rho_{A}, R_{H}$, the larger of the two values at which $V_{A}^{d d}=V_{A}^{n i}$, is less than $R_{A Z}$. For $R$ in the range $R_{H} \leq R<R_{A Z}$, firm A once again maximizes value with dual distribution. Theorem 1M has in common with Theorem 1L that as $R$ approaches $R_{A Z}$, firm A loses value on its downstream operation if the downstream operation is viewed as a stand-alone operation, but it is value-maximizing for the firm as a whole to participate in the downstream market to mitigate double-marginalization by firm B.

\footnotetext{
${ }^{19}$ We assume $\frac{k_{A}}{\rho_{A}} \leq \frac{1}{4}$. Theorem $1 \mathrm{M}$ applies for values of $\frac{k_{A}}{\rho_{A}}$ that fall in a range of length $\frac{1}{288} \frac{\left(1-\sigma^{2}\right)\left(1+\sigma^{2}\right)^{2}\left(8+\sigma^{2}\right)}{7+\sigma^{2}}$. This length fluctuates between 1.5 and 2 per cent of $1 / 4$ for approximately the range $0 \leq \sigma \leq 0.7$, and falls rapidly to zero for larger values of $\sigma$.
} 


\subsection{Discussion}

Note that we consider a situation in which all firms make entry decisions de novo. Firm B makes its entry decision only after firm A has announced its wholesale price. Contrast this with the case of a deus ex machina increase in the quality of firm A's variety (a reduction in $R$ ), after firm B has committed sunk assets, and assume there is unconstrained dual distribution. Such a shift would result in an increase in the unconstrained wholesale price $\omega^{d d}$, in decreases in $p_{A}, p_{B}$, and in a decrease in firm B's margin over variable cost, $p_{B}-\omega \rho_{B} \cdot{ }^{20}$ Firm B's margin over variable cost might remain sufficient to cover its average fixed cost but not the average capitalized value of sunk entry cost. Such a change would appear to the owners of firm B to be a vertical price squeeze; from an economic point of view, it would be more a stranded asset problem. ${ }^{21}$ A sufficiently great reduction in $R$ might make firm A switch to constrained dual distribution or even to exclusion. In the latter case, this change, although nonstrategic, might well reduce consumer welfare (it would certainly reduce consumer choice, from two varieties to one). We therefore turn to the transfer price rule and its impact on market performance.

\section{The transfer price rule}

In what follows, we focus on values of $\frac{k_{A}}{\rho_{A}}$ for which Theorem $1 \mathrm{~L}$ holds,

$$
\frac{k_{A}}{\rho_{A}} \leq \frac{1}{4} \frac{3+\sigma^{2}}{7+\sigma^{2}}
$$

so that in the absence of the transfer price rule, firm A would opt for constrained or unconstrained dual distribution for $R_{1} \leq R \leq R_{A Z}$.

The transfer price rule requires that firm A's downstream operation should realize a nonnegative pseudo-profit in the counterfactual case that it has to purchase the essential input on the same terms as firm B, that is

$$
\left(p_{A}^{d d}-\omega^{d d} \rho_{A}\right) q_{A}^{d d}-\left(F_{A}+r E_{A}\right) \geq 0,
$$

with $d u o=d d, c d d$, or equivalently that

$$
\frac{r}{N} \frac{\widehat{V}_{A D}}{\rho_{A}}-\frac{k_{A}}{\rho_{A}}=\frac{p_{A}^{d u o}-\omega^{d d} \rho_{A}}{\rho_{A}} \frac{q_{A}^{d u o}}{N}-\frac{k_{A}}{\rho_{A}} \geq 0,
$$

where $\widehat{V}_{A D}$ is the pseudo-value of firm A's downstream operation, before allowing for capital cost.

\footnotetext{
${ }^{20}$ These comparative static changes are intuitive, and follow formally from results in the Appendix.

${ }^{21}$ If the owners of firm B paid sunk entry costs out of their own pockets, they would bear the loss in value. If the owners of firm B financed sunk entry costs and, being unable to make interest payments, lost control of the firm, lenders would bear the loss in value. In either case the assets, being sunk, would remain in the market.
} 


\subsection{When would the TPR be a binding constraint?}

We first ask for what values of $R, \sigma$, and $\frac{k_{A}}{\rho_{A}}$ the transfer price rule would be a binding constraint. Considering first the unconstrained dual distribution regime, this requires us to analyze the gross pseudo-value function of firm A's downstream operation,

$$
\frac{r}{N} \frac{\widehat{V}_{A D}}{\rho_{A}}=\frac{3}{2} \frac{\sigma^{2}}{\left(1-\sigma^{2}\right)\left(8+\sigma^{2}\right)^{2}} \frac{(R-\sigma)(2 R+\sigma)\left(R_{A Z}-R\right)}{R} .
$$

The TPR is a binding constraint if

$$
\frac{r}{N} \frac{\widehat{V}_{A D}}{\rho_{A}} \leq \frac{k_{A}}{\rho_{A}}
$$

and the equality version of (41) is a cubic equation in $R$.

From (40), it appears that $\widehat{V}_{A D}=0$ for two positive values of $R$, i.e., $R=\sigma$ and $R=R_{A Z}$. We can moreover show that $\widehat{V}_{A D}$ rises from 0 at $R=\sigma$, attains a maximum for a value $R^{*}$ that lies between $\sigma$ and $R_{A Z}$, and declines for larger values of $R .^{22}$ We can identify this value $R^{*}$ and write the analytical expression for the maximum value $\widehat{V}_{A D}^{*}$ of firm A's gross downstream pseudo-value.

If

$$
\frac{r}{N} \frac{\widehat{V}_{A D}^{*}}{\rho_{A}} \leq \frac{k_{A}}{\rho_{A}} \leq \frac{1}{4} \frac{3+\sigma^{2}}{7+\sigma^{2}}
$$

the TPR is a binding constraint for all $R$ that satisfy the condition of Theorem 1L. In what follows, we consider values of $\frac{k_{A}}{\rho_{A}}$ that satisfy (42). ${ }^{23}$

The lower bound of the unconstrained dual distribution range is $R=R_{B}$, not $R=\sigma$. We have discussed $R=\sigma$ because it is a root of $\widehat{V}_{A D}=0$. For $R<R_{B}$, the value of the wholesale price used to define the pseudo-value of firm A's downstream operation is the constrained optimal value, $\omega^{c d d}$, not $\omega^{d d}$. As $R$ falls below $R_{B}$, the relative quality of firm A's variety increases, and the pseudo-profit of firm A's downstream division rises.

When there is constrained dual distribution, the transfer price rule is a binding constraint for $R_{c T}<R<R_{B}{ }^{24}$ For $R<R_{c T}$, the relative quality of firm A's variety is sufficiently great that the transfer price rule ceases to be a binding constraint (that is, (41) does not hold).

\footnotetext{
${ }^{22}$ That is, $\left.\frac{\partial \widehat{V}_{A D}}{\partial R}\right|_{R=\sigma}>0,\left.\frac{\partial \widehat{V}_{A D}}{\partial R}\right|_{R=R_{A Z}}<0$, and $\frac{\partial^{2} \widehat{V}_{A D}}{\partial R^{2}}<0$.

${ }^{23}$ What if (42) is not satisfied? Recall that $\widehat{V}_{A D}^{*}$ is an inverted-U-shaped function of $R$ over
} the range $\sigma \leq R \leq R_{A Z}$. If $\frac{k_{A}}{\rho_{A}}<\frac{r}{N} \frac{\widehat{V}_{A D}^{*}}{\rho_{A}}$, then the horizontal line at height $\frac{k_{A}}{\rho_{A}}$ cuts this function at two values of $R, R_{b L}$ and $R_{b H}$. The TPR would be a binding constraint over the ranges $\sigma \leq R \leq R_{b L}$ and $R_{b H} \leq R \leq R_{A Z} . R_{b L}$ and $R_{b H}$ are roots of a cubic equation. We limit attention to values of $\frac{k_{A}}{\rho_{A}}$ for which the TPR would bind throughout the relevant range of $R$ on the argument that if we understand how the TPR would affect market performance if it is a binding constraint over the entire range of $R$, then we will understand how it affects market performance when it is a binding constraint over only a subset of the relevant range of $R$.

${ }^{24} R_{c T}$ is a root of the equation $\frac{r}{N} \frac{\widehat{V}_{A D}\left(\omega^{c d d}\right)}{\rho_{A}}=\frac{k_{A}}{\rho_{A}}$. 


\subsection{If the TPR is a binding constraint}

If the TPR is a binding constraint, firm A will set $\omega$ and $p_{A}$ so that the constraint holds with equality,

$$
\frac{p_{A}}{\rho_{A}} \frac{q_{A}}{N}-\frac{k_{A}}{\rho_{A}}=\omega \frac{q_{A}}{N}
$$

To do otherwise would involve a needless sacrifice of value.

Substituting for stage III values of $\frac{p_{A}}{\rho_{A}}$ and $\frac{q_{A}}{N}$ as functions of $\omega$ in (43) yields a quadratic equation that determines the TPR-constrained value of $\omega$. Given this value $\omega^{T P R}$, all stage III quantities of interest are determined.

The TPR obliges firm A to set a price $p_{A}$ and wholesale price per unit of quality $\omega$ so that its downstream operation breaks even in the counterfactual, pseudo-value sense. Although the TPR forces firm A to act as if its downstream operation pays $\omega \rho_{A}$ per unit of the essential input, firm A still bases its distribution choice on its actual (but TPR-constrained) dual-distribution value. Thus one should expect that the imposition of the TPR will change the values of $R$ at which firm A's optimal distribution option will shift from exclusion to dual distribution to nonintegration. ${ }^{25,26}$

Figure 6 shows firm A's value-maximizing choice of distribution mode in $(R, \sigma)$-space, if firm $\mathrm{A}$ is subject to the TPR. The regions in which firm $\mathrm{A}$ would opt for alternative distribution modes have the general configuration of the no-TPR regime (Figure 4). If the TPR is in place, the transition from the range of $R \mathrm{~s}$ where firm B's participation constraint is binding to the region in which firm B's participation constraint is not binding and the transition from dual distribution to nonintegration take place at lower values of $R$ than when there is no TPR, for a given value of $\sigma$. With the TPR, the dual distribution region ends at a lower level of $\sigma$ than without the TPR.

\subsection{Numerical analysis}

There are no analytical solutions if the TPR is a binding constraint. We illustrate the consequences of the TPR for parameter values ${ }^{27}$ that are central in

\footnotetext{
${ }^{25}$ In its 1967 Schwinn decision (U.S. $v$. Arnold, Schwinn \& Co. et al. 388 U.S. 365 (1967)), the U.S. Supreme Court held that Schwinn could not impose nonprice restraints on independent distributors that had taken title to bicycles intended for resale. Following this decision, Schwinn internalized the distribution function, cutting off distributors with which it had had decades-long relationships.

${ }^{26} \mathrm{EU}$ competition policy holds that a dominant firm cannot deny an existing customer normal supplies merely because the dominant firm decides to enter a downstream market (Commercial Solvents (Joined Cases 6/73 and 7/73 Istituto Chemioterapico Italiano and Commercial Solvents $v$ Commission [1974] ECR 223.)). But GlaxoSmithKline/Spain (GlaxoSmithKline Services Unlimited $v$. Commission Case C 501/06 P 17 December 2008) contains a recognition that it is not useful to place a firm, even a dominant firm, in a situation where its options are to lose money or to withdraw from a market entirely. The implications of these precedents, as is or in combination with the TPR, for distribution choices by dominant firms under EU competition policy, are unclear.

${ }^{27}$ The parameter values used for Figures (7)-(9) are $k_{A}=k_{B}=1 / 40, \sigma=1 / 2, \rho_{A}=1$. The latter is a normalization. Given $\rho_{A}=1, \rho_{B}$ varies with $R$. Other parameters $(r, N)$ cancel out in the expressions for the ratios that are shown in the figures.
} 


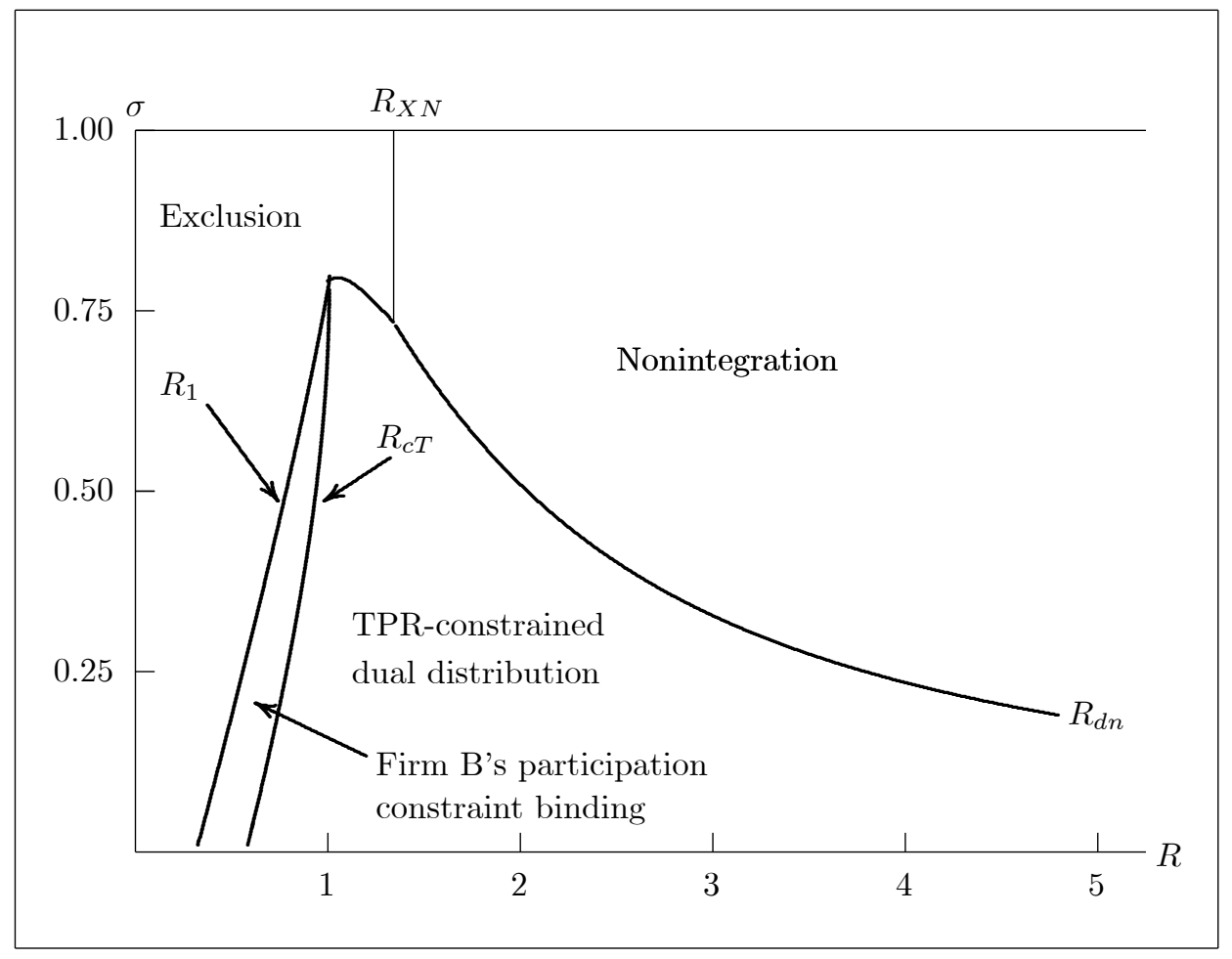

Figure 6: Firm A's choice of distribution mode, when subject to the transfer price rule, low $k_{A}$, low $k_{B}$.

the sense that for these values, firm A will opt for exclusion, dual distribution, or nonintegration, depending on $R$. We examine the consequences of the TPR for firm A's choice of distribution mode and for market performance. We also discuss qualitative changes in the results for other sets of parameter values.

\subsubsection{Low $k_{A}, k_{B}$}

Figures (7)-(9) show the impact of the TPR on firm values, on wholesale and retail prices, and on consumer surplus and net social welfare, ${ }^{28}$ respectively. For each variable, the figures show the TPR-constrained value as a fraction of the corresponding no-TPR value.

For these parameter values, the TPR is a binding constraint for $R_{c T} \leq R \leq$ $R_{A Z}$. For $R<R_{c T}$, the relative quality of firm A's variety is so great that its downstream unit would have a positive pseudo-value at $\omega=\omega^{\text {cdd }}$. At the other extreme, for $R \geq R_{A Z}$, firm A would opt for nonintegration in any case, since its dual-distribution output is zero.

\footnotetext{
${ }^{28} \mathrm{Net}$ social welfare is the sum of firm values and the present-discounted value of consumer surplus.
} 


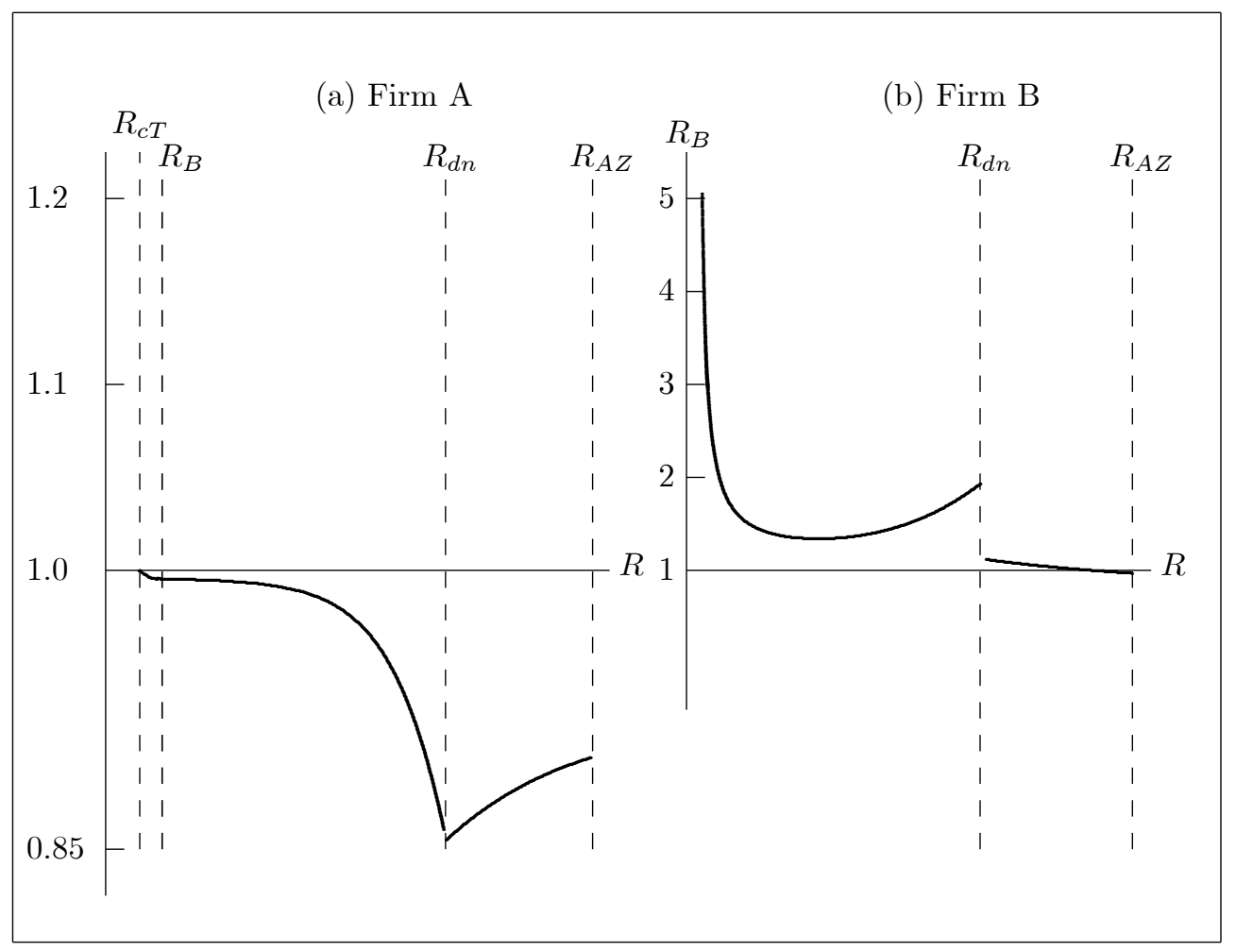

Figure 7: Relative firm values, with TPR relative to without TPR, low $k_{A}, k_{B}$. See text for explanation of regions of the horizontal axis.

As shown in Figure 7(a), the TPR reduces firm A's value for all $R_{c T} \leq$ $R \leq R_{A Z}$. When the TPR is imposed, firm A chooses dual distribution for $R_{c T} \leq R \leq R_{d n}$, where $R_{d n}$ is the relative quality level at which firm A switches from dual distribution to nonintegration if it is subject to the TPR. ${ }^{29}$ Without the TPR, however, firm A would choose dual distribution subject to firm B's participation constraint for $R_{c T} \leq R \leq R_{B}$, and would choose dual distribution for $R_{B} \leq R \leq R_{A Z}$. For $R_{d n}<R_{A Z}$, firm A would choose nonintegration if subject to the TPR but dual distribution without the TPR. The imposition of the TPR changes firm A's incentives and induces it to withdraw from distribution at a lower relative quality level than is the case without the TPR.

Correspondingly, the TPR increases firm B's relative value for all $R_{c T}<$ $R \leq R_{d n}$ and for much of the range $R_{d n} \leq R \leq R_{A Z} \cdot{ }^{30}$ For low levels of $R$ in that range, the absolute level of firm B's value (with or without the TPR)

\footnotetext{
${ }^{29} R_{d n}$ must be solved for numerically. See the discussion in the Appendix that is available on request from the authors.

${ }^{30}$ Figure 7 (b) shows firm B's relative firm value for $R_{B}<R \leq R_{A Z}$. Firm $\mathrm{B}$ has positive TPR-constrained value for $R_{c T} \leq R \leq R_{B}$. Over this range, it is the constrained dual distribution regime that reigns in the absence of the TPR, and firm B's value is zero.
} 


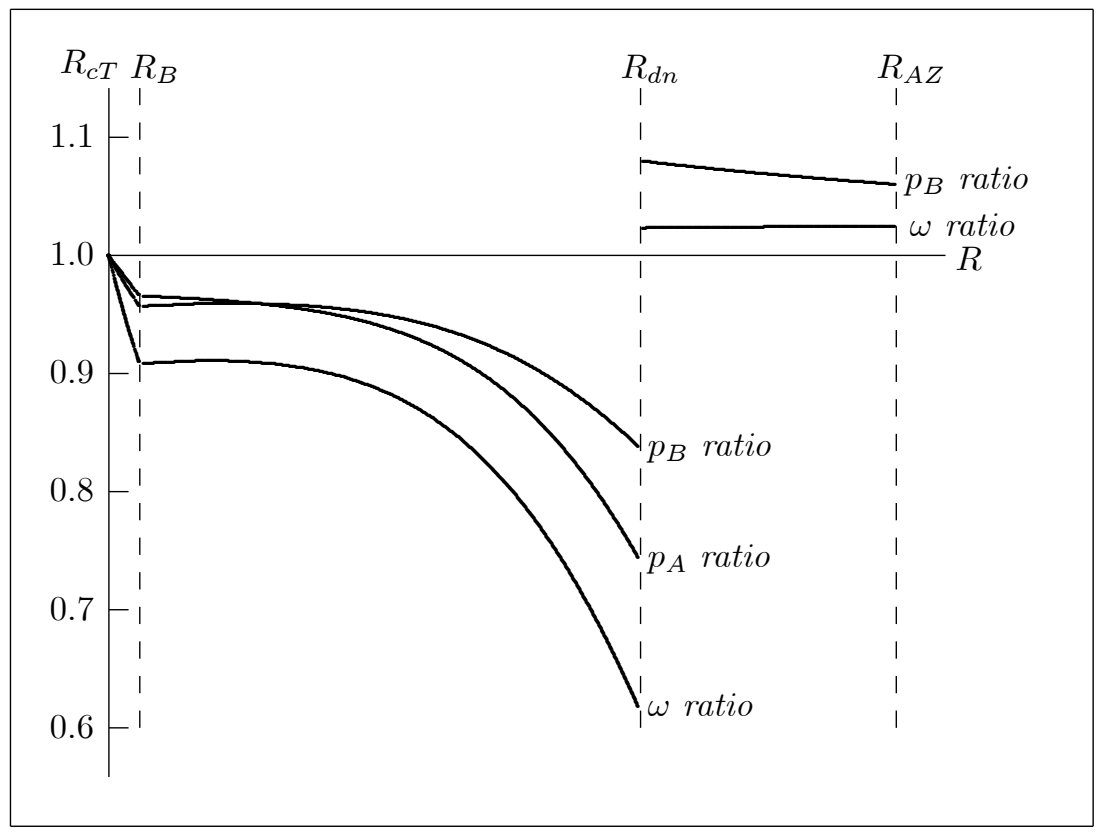

Figure 8: Relative wholesale and retail prices, with TPR relative to without $\mathrm{TPR}$, low $k_{A}, k_{B}$. See text for explanation of regions of the horizontal axis.

is small, but the relative increase in firm B's value under the TPR is large. As long as firm A finds it optimal to integrate forward, the TPR further increases firm B's value. If firm A does not integrate forward, it sets a relatively high $\omega,{ }^{31}$ and firm B's value is essentially what it would be without the TPR (the ratio shown in Figure 7(b) is near 1).

Underlying the value changes shown in Figure 7 are the changes in $\omega, p_{A}$, and $p_{B}$ shown in Figure 8. As long as firm A integrates forward, the TPR obliges it to lower the price of firm B's essential input. It is to be expected that where $\omega$ leads, $p_{B}$ follows, and this is indeed the case. As is also to be expected in price-setting duopoly, as the equilibrium value of $p_{B}$ falls, the equilibrium value of $p_{A}$ falls as well. But if the TPR induces firm A to withdraw from distribution, there are modest relative increases in both $\omega$ and $p_{B}$.

The changes in relative consumer surplus and relative net social welfare shown in Figure 9 mirror the price changes shown in Figure 8. If the TPR is in place, for values of $R$ for which dual distribution is firm A's value-maximizing choice, the TPR substantially increases consumer surplus, and increases net social welfare as well. For values of $R$ that induce firm A not to integrate into distribution under the TPR, the TPR significantly reduces consumer surplus, and reduces net social welfare as well.

\footnotetext{
${ }^{31}$ Without an operating downstream division, firm $\mathrm{A}$ is not constrained in its choice of $\omega$. The impact of the TPR is to change firm A's choice of distribution mode.
} 


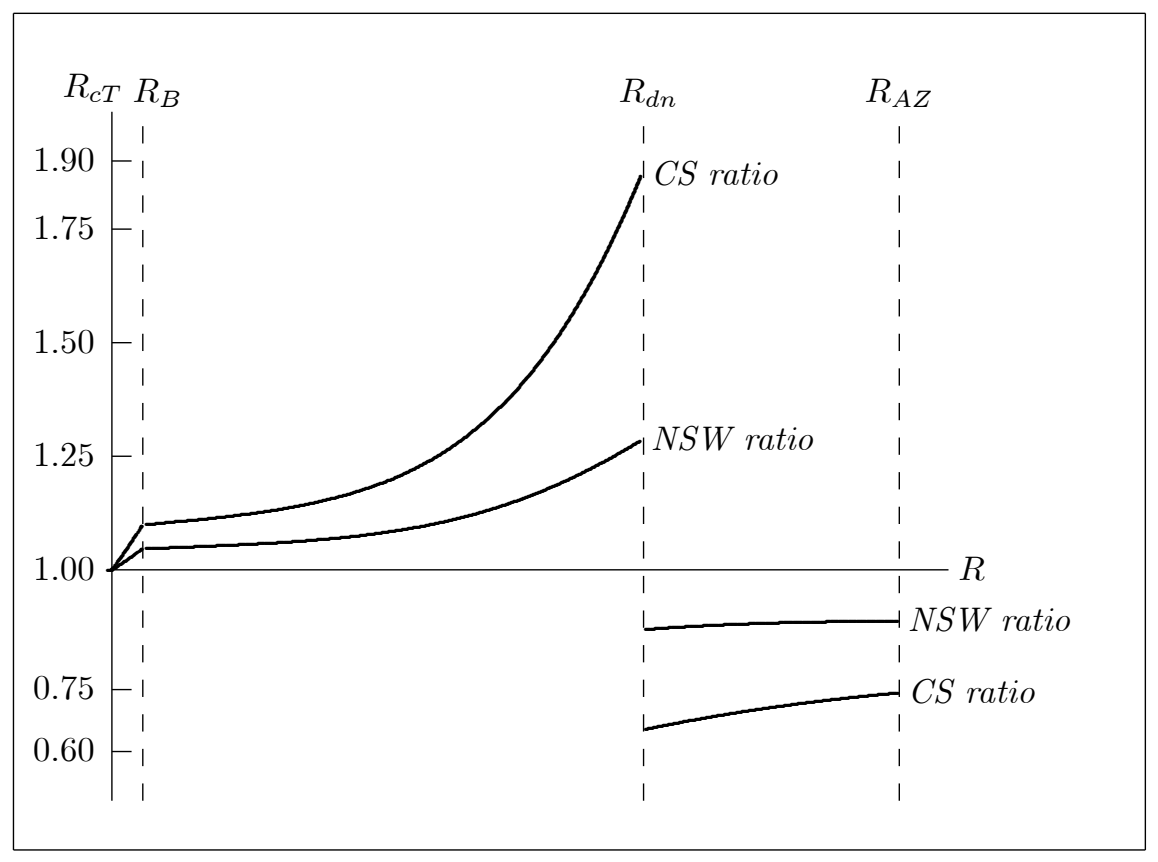

Figure 9: Consumer surplus and net social welfare, with TPR relative to without $\mathrm{TPR}$, low $k_{A}, k_{B}$. See text for explanation of regions of the horizontal axis.

Assessment To cast these results in the light most favorable to the transfer price rule, one might argue that one should expect values of $R$ modestly greater than 1 - a local supplier is probably more in tune with the local market than would be a division of an integrated (perhaps multinational) firm - but not substantially so. For the simulations discussed above, $R_{c T}$ is slightly smaller than $1, R_{B}$ slightly more than 1 , and $R_{d n}$ slightly larger than $2 . R$ in the neighborhood of 2 implies $\rho_{B}$ is roughly 4 times $\rho_{A}$. Probably one would not expect the maximum reservation price for a local variety to be more than four times the maximum reservation price of the variety of an integrated firm. If this expectation is valid, the transfer price rule would have a moderate positive effect on consumer surplus and on net social welfare.

Evidently, however, this argument is conditional on firm A integrating into distribution if subject to the transfer price rule. If, under the influence of the TPR, firm A does not integrate into distribution, double marginalization implies a worsening of market performance. We turn, therefore, to discussion of the impact of the transfer price rule for other sets of parameter values, in particular larger $k \mathrm{~s}$. 


\subsubsection{Robustness}

The transfer price rule requires firm $\mathrm{A}$ to set $\omega$ and $p_{A}$ in such a way that its downstream unit would at least break even as a stand-alone entity paying the same wholesale price per unit of quality as firm B. The downstream firm's revenue must cover its fixed cost and a normal rate of return on its sunk entry cost. It is not surprising, therefore, that simulation results are sensitive to the value chosen for $k_{A}$, firm A's fixed cost and normal return on entry cost per capital. Holding other parameter values fixed (including $k_{A}=1 / 40$ ) and making $k_{B}$ four times as large as $k_{A}$ (that is, $k_{B}=1 / 10$, near the maximum value consistent with constraints) does not change the qualitative nature of the results. If the TPR is imposed, for sufficiently low values of $R\left(R_{c T}<R<R_{d n}\right)$, firm A opts for dual distribution with $\omega$ set at its TPR-constrained value. For $R$ in this range, firm A's value is reduced. All other welfare elements, including net social welfare, increase. But the TPR induces firm A to opt for nonintegration at a much lower level of $R$ than would otherwise be the case (indeed, $R_{d n}<R_{A Z}$ ). If firm $\mathrm{A}$ is not integrated into distribution, double marginalization has a negative impact on both consumer surplus and on net social welfare.

If, in contrast, $k_{B}(=1 / 40)$ and all other parameters are held at the values of Section 4.3.1, but if $k_{A}$ is made four times as large as $k_{B}$ (that is, 1/10), then firm $\mathrm{A}$, if subject to the TPR, never maximizes value with dual distribution. It excludes firm $\mathrm{B}$ for all values of $R$ for which there would be constrained dual distribution, and for part of the range of $R$ for which there would be unconstrained dual distribution, without the TPR. Due to the imposition of the TPR, nonintegration is firm A's value-maximizing choice at a much lower relative quality level than would otherwise be the case.

When the TPR induces firm A to exclude, firm A's value, consumer surplus, and net social welfare are all reduced.$^{32}$ For higher $R$, but well within the range of $R$ that would result in dual distribution without the TPR, firm A maximizes value by nonintegration if subject to the TPR. This increases firm B's value, relative to the situation without the TPR, but reduces firm A's value, consumer surplus, and net social welfare.

If $k_{A}$ and $k_{B}$ are both increased by a factor of four (that is, $k_{A}=k_{B}=1 / 10$ ), holding other parameter values at previous levels, results are qualitatively the same as if $k_{A}$ alone is at the higher level $\left(k_{A}=1 / 40, k_{B}=1 / 10\right)$.

In short, positive arguments for the TPR can be made, if the quality of firm B's variety is only moderately greater than the quality of firm A's variety and firm A has relatively low fixed cost and sunk entry cost. However, the impact of the TPR on market performance is entirely negative if firm A has high fixed cost and sunk entry cost, relative to the size of the market. In such cases, the effect of the TPR is to short-circuit competition. For low $R$, only firm A's variety is available to final consumers while only firm $B$ 's variety, admittedly of higher quality, is available to final consumers. But double marginalization makes firm B's variety available on terms that leave consumers worse off than would be the case absent the TPR.

\footnotetext{
${ }^{32}$ With internalization, firm $\mathrm{B}$ does not operate.
} 


\section{Conclusion}

\subsection{Economics}

What we see is that the transfer price rule improves market performance as long as firm A remains in the downstream market. If firm A does not integrate forward into distribution, the transfer price rule worsens market performance, for values of $R$ for which firm A would opt for dual distribution, without the TPR but for nonintegration with the TPR. These results are consistent with empirical evidence (Lafontaine and Slade, 2005, p. 21):

While different theoretical models often yield diametrically opposed predictions as to the welfare effects of vertical restraints, we find that in the setting that we focus on, namely manufacturer/retailer or franchisor/franchisee relationships, the empirical evidence concerning the effects of vertical restraints on consumer well-being is surprisingly consistent. Specifically, it appears that when manufacturers choose to impose such restraints, not only do they make themselves better off, but they also typically allow consumers to benefit from higher quality products and better service provision.

\subsection{Policy implications}

The words of Section 2 of the Sherman Act refer to monopolization. The life that judicial interpretation has breathed into this clay deals with conduct that is exclusionary. The Article $102 \mathrm{EU}$ Treaty prohibition of abuse of a dominant position is more complex, touching on exclusionary conduct but also on the exercise of market power and evincing a special responsibility of dominant firms to conduct themselves in such a way that competition in the single market is not distorted.

The question of the appropriate antitrust treatment of vertical pricing is intimately related to the evolution of antitrust policy from reliance on competition tout court to get good market performance ${ }^{33}$ to an explicit evaluation of the impact of business practices on market performance in general and consumer welfare in particular.

Here the implications of our model are ambiguous, in the following sense. For some parameter values, the TPR improves market performance (consumer surplus and net social welfare) by altering the terms of competition (rivalry) between integrated and nonintegrated firms. This would suggest imposing the TPR as a means of promoting competition. But for other parameter values, imposing the TPR worsens market performance, either by inducing the upstream firm to withdraw from distribution or by inducing the upstream firm to internalize distribution, in both cases reducing competition in the sense of rivalry.

${ }^{33}$ This can be traced to the 1904 Northern Securities decision (193 U.S. 197 (1904)). 
The tension here is that "competition" will sometimes improve market performance and sometimes worsen it, but explicit evaluation of the welfare impact of the transfer price rule on market performance in particular circumstances would seem, as a practical matter, to be beyond the competence of courts to carry out.

For U.S. antitrust policy, a suggested resolution of the tension between reliance on competition and explicit evaluation of the impact of (in this case) the TPR on market performance may be found in Posner's (2001, pp. 194-195) view that the proper target of Section 2 is business conduct that would exclude equally efficient competitors. In this perspective, a vertically-integrated firm that sells an essential input to nonintegrated downstream firms with which it also competes is more efficient than those downstream firms because it is vertically integrated.$^{34}$ It may be that because the integrated firm has a cost/quality advantage vis-à-vis its nonintegrated downstream customer/rival, it is profitable for it to set a wholesale price that makes the downstream firm unprofitable. But the profitability of such a wholesale price is not strategic in the sense of being conditional on the exit of the downstream rival.

In the absence of exclusionary behavior upstream, the upstream market will reach an equilibrium market structure dictated by the size of the upstream market and nature the upstream technology. If that equilibrium market structure is a monopoly (which may well be the case for the telecommunications markets that have been home to recent price squeeze complaints) that may be an argument for regulation. ${ }^{35}$ It is not, or at least, our model does not make it, an argument for altering the terms of rivalry between integrated and nonintegrated firms when the implications of such alteration for market performance can be seen only through a glass darkly. ${ }^{36}$

\section{Appendix}

Here we state results. Derivations are given in a separate appendix available on request from the authors.

\footnotetext{
${ }^{34}$ See also Motta and de Streel (2006, pp. 115-116, emphasis in original): "Thus, only a margin squeeze that excludes a competitor that is more efficient than the vertically integrated firm would be anticompetitive and should be condemned."

${ }^{35}$ In the 1990 Town of Concord case (915 F. 2d 17 (1st Cir., 1990)), then-Judge Breyer wrote a decision to the effect that regulation precluded consideration of price squeeze allegations as an antitrust violation.

${ }^{36}$ The implications of our model for the role of the TPR in EU competition policy, with its recessive gene that would have dominant firms act "as if" they operated in a competitive market, are less obvious. It seems clear, however, that the first part of the argument the U.S. Supreme Court used to partition "alleged price squeeze" into "upstream exercise of market power" and "alleged predation" will not fly for EU competition policy. In principle, honored perhaps more often in the breach than the observance, the exercise of market power is an abuse of a dominant position.
} 


\subsection{Table 1}

Column 1 of Table 1 is the monopoly outcome, with demand determined by the quality of firm A's variety. Column 2 is the double marginalization outcome, with demand determined by the quality of firm B's variety.

\subsection{Dual distribution}

Inverse demands are given by equation (2), for $i, j=A, B$ and $i \neq j$. The corresponding demand equations are

$$
q_{A}=\frac{N}{1-\sigma^{2}}\left[\frac{\rho_{A}-p_{A}}{\rho_{A}}-\sigma \sqrt{\frac{\rho_{B}}{\rho_{A}}} \frac{(1-\omega) \rho_{B}-\left(p_{B}-\omega \rho_{B}\right)}{\rho_{B}}\right]
$$

and

$$
q_{B}=\frac{N}{1-\sigma^{2}}\left[\frac{(1-\omega) \rho_{B}-\left(p_{B}-\omega \rho_{B}\right)}{\rho_{B}}-\sigma \sqrt{\frac{\rho_{A}}{\rho_{B}}} \frac{\rho_{A}-p_{A}}{\rho_{A}}\right] .
$$

\subsubsection{Stage III}

$\omega$ is given, having been determined in stage II. Values $V_{A}^{d d 3}$ and $V_{B}^{d d 3}$ satisfy

$$
\begin{gathered}
\frac{1-\sigma^{2}}{N}\left(r V_{A}^{d d 3}+F_{A}+r E_{A}\right)= \\
p_{A}\left[\frac{\rho_{A}-p_{A}}{\rho_{A}}-\sigma \sqrt{\frac{\rho_{B}}{\rho_{A}}} \frac{(1-\omega) \rho_{B}-\left(p_{B}-\omega \rho_{B}\right)}{\rho_{B}}\right]+ \\
\omega \rho_{B}\left(\frac{\rho_{B}-p_{B}}{\rho_{B}}-\sigma \sqrt{\frac{\rho_{A}}{\rho_{B}}} \frac{\rho_{A}-p_{A}}{\rho_{A}}\right)
\end{gathered}
$$

and

$$
\begin{gathered}
\frac{1-\sigma^{2}}{N}\left(r V_{B}^{d d 3}+F_{B}+r E_{B}\right)= \\
\left(p_{B}-\omega \rho_{B}\right)\left[\frac{(1-\omega) \rho_{B}-\left(p_{B}-\omega \rho_{B}\right)}{\rho_{B}}-\sigma \sqrt{\frac{\rho_{A}}{\rho_{B}}} \frac{\rho_{A}-p_{A}}{\rho_{A}}\right],
\end{gathered}
$$

respectively.

The first-order conditions to maximize $V_{A}^{d d 3}$ and $V_{B}^{d d 3}$ are

$$
2 \frac{p_{A}}{\rho_{A}}-\sigma \sqrt{\frac{\rho_{B}}{\rho_{A}}} \frac{p_{B}-\omega \rho_{B}}{\rho_{B}}=1-\sigma \sqrt{\frac{\rho_{B}}{\rho_{A}}}+2 \sigma \sqrt{\frac{\rho_{B}}{\rho_{A}}} \omega
$$

and

$$
-\sigma \sqrt{\frac{\rho_{A}}{\rho_{B}}} \frac{p_{A}}{\rho_{A}}+2 \frac{p_{B}-\omega \rho_{B}}{\rho_{B}}=1-\sigma \sqrt{\frac{\rho_{A}}{\rho_{B}}}-\omega
$$

respectively.

Equilibrium price-cost margins satisfy

$$
\left(4-\sigma^{2}\right) \frac{p_{A}}{\rho_{A}}=\left(2-\sigma^{2}\right)-R \sigma+3 R \sigma \omega
$$


and

$$
\left(4-\sigma^{2}\right) \frac{p_{B}-\omega \rho_{B}}{\rho_{B}}=\left(2-\sigma^{2}\right)-\frac{\sigma}{R}-2\left(1-\sigma^{2}\right) \omega .
$$

Where the first-order conditions hold, quantities demanded are

$$
q_{A}=\frac{N}{1-\sigma^{2}}\left(\frac{p_{A}}{\rho_{A}}-R \sigma \omega\right)
$$

and

$$
q_{B}=\frac{N}{1-\sigma^{2}} \frac{p_{B}-\omega \rho_{B}}{\rho_{B}} .
$$

Values as functions of $\omega$ satisfy

$$
\begin{gathered}
\frac{\left(1-\sigma^{2}\right)\left(4-\sigma^{2}\right)^{2}}{N}\left(r V_{A}^{d d 2}+F_{A}+r E_{A}\right)=\rho_{A}\left(2-\sigma^{2}-R \sigma\right)^{2} \\
+\left(1-\sigma^{2}\right)\left(8+\frac{\sigma^{3}}{R}\right) \omega \rho_{B}-\left(1-\sigma^{2}\right)\left(8+\sigma^{2}\right) \omega^{2} \rho_{B}
\end{gathered}
$$

and

$$
\frac{1-\sigma^{2}}{N}\left(r V_{B}^{d d 2}+F_{B}+r E_{B}\right)=\rho_{B}\left(\frac{p_{B}-\omega \rho_{B}}{\rho_{B}}\right)^{2}
$$

\section{$6.2 .2 \omega$}

The first-order condition to maximize $V^{d d 2}$ gives firm A's optimal wholesale price, (17). Substituting (17) in the appropriate stage 3 expressions gives stage II equilibrium values.

Price-cost margins are

$$
\frac{p_{A}^{I I I}}{\rho_{A}}=\frac{1}{2} \frac{1}{8+\sigma^{2}}\left(8-\sigma^{2}+2 R \sigma\right)
$$

and

$$
\frac{p_{B}^{I I I}-\omega \rho_{B}}{\rho_{B}}=\frac{2+\sigma^{2}}{8+\sigma^{2}}\left(1-\frac{\sigma}{R}\right) .
$$

Quantities demanded are (18) and (19).

Values satisfy

$$
\begin{gathered}
4 \frac{\left(1-\sigma^{2}\right)\left(8+\sigma^{2}\right)}{N}\left(r V_{A}^{d d 2}+F_{A}+r E_{A}\right)= \\
\rho_{A}\left(8-3 \sigma^{2}-\sigma^{4}-8 R \sigma+4 R^{2}\right)
\end{gathered}
$$

and

$$
\frac{1-\sigma^{2}}{N}\left(r V_{B}^{d d 2}+F_{B}+r E_{B}\right)=\left(\frac{2+\sigma^{2}}{8+\sigma^{2}}\right)^{2} \rho_{B}\left(1-\frac{\sigma}{R}\right)^{2} .
$$




\subsection{Transfer Price Rule}

The transfer price rule requires that firm A's downstream unit make a nonnegative pseudo-profit in the counterfactual case that it purchases the essential input at the same price as firm B. The transfer price rule is a binding constraint if

$$
\left(p_{A}-\omega \rho_{A}\right) q_{A}<F_{A}+r E_{A}
$$

where the left-hand side is evaluated for unconstrained equilibrium values.

Equilibrium values satisfy

$$
\begin{gathered}
\frac{q_{A}}{N}=\frac{3 \sigma}{\left(1-\sigma^{2}\right)\left(8+\sigma^{2}\right)}\left[\frac{\left(1-\sigma^{2}\right)\left(8+\sigma^{2}\right)}{6 \sigma}-(R-\sigma)\right] \\
\frac{p_{A}-\left(c_{A}+\omega\right) \rho_{A}}{\rho_{A}}=\frac{\sigma(R-\sigma)(2 R+\sigma)}{2\left(8+\sigma^{2}\right) R},
\end{gathered}
$$

and the transfer price rule is a binding constraint if

$$
\frac{3}{2} \frac{\sigma^{2}}{\left(1-\sigma^{2}\right)\left(8+\sigma^{2}\right)^{2}} \frac{(R-\sigma)(2 R+\sigma)}{R}\left[\frac{\left(1-\sigma^{2}\right)\left(8+\sigma^{2}\right)}{6 \sigma}-(R-\sigma)\right]<\frac{k_{A}}{\rho_{A}}
$$

or alternatively if

$$
\frac{\sigma}{2\left(8+\sigma^{2}\right)} \frac{(R-\sigma)(2 R+\sigma)}{R}\left[\frac{1}{2}-\frac{3 \sigma}{\left(1-\sigma^{2}\right)\left(8+\sigma^{2}\right)}(R-\sigma)\right]<\frac{k_{A}}{\rho_{A}} .
$$

The range of relative qualities consistent with dual distribution differs as $\frac{k_{A}}{\rho_{A}} \leq \frac{1}{4} \frac{3+\sigma^{2}}{7+\sigma^{2}}$ or $\frac{k_{A}}{\rho_{A}}>\frac{1}{4} \frac{3+\sigma^{2}}{7+\sigma^{2}}$. Consider each case in turn.

Small $\frac{k_{A}}{\rho_{A}} \quad$ There is a range of $R$ consistent with dual distribution if

$$
R_{B}=\sigma+\frac{8+\sigma^{2}}{2+\sigma^{2}} \sqrt{\frac{1-\sigma^{2}}{\rho_{A}} k_{B}} \leq \sigma+\frac{\left(1-\sigma^{2}\right)\left(\sigma^{2}+8\right)}{6 \sigma}
$$

or equivalently if

$$
\frac{\left(2+\sigma^{2}\right)^{2}\left(1-\sigma^{2}\right)}{36 \sigma^{2}}>\frac{k_{B}}{\rho_{A}} .
$$

If this condition is not met, firm A's equilibrium distribution choice as $R$ rises switches directly from refusal to deal to nonintegration. Assume (66) holds, and consider the left-hand side of (64) over the maximum possible range of $R$,

$$
\sigma \leq R \leq \sigma+\frac{\left(1-\sigma^{2}\right)\left(\sigma^{2}+8\right)}{6 \sigma}
$$

The left-hand-side of (64) is zero for $R=\sigma$ (since $R=\sigma$ makes $\frac{p_{A}-c_{A} \rho_{A}-\omega \rho_{A}}{\rho_{A}}=$ 0 ), and zero for $R=\sigma+\frac{\left(1-\sigma^{2}\right)\left(\sigma^{2}+8\right)}{6 \sigma}$ (since this value of $R$ makes $\frac{q_{A}}{N}=0$ ). The 
first derivative of the left-hand side of (64) is positive for $R=\sigma$ and negative for $R=\sigma+\frac{\left(1-\sigma^{2}\right)\left(\sigma^{2}+8\right)}{6 \sigma}$. The second derivative of the left-hand side of (64) is negative. Over the relevant range of $R$, the left-hand side of (64) thus begins at zero, rises to a maximum, and falls to zero again, taking a single maximum value. If this maximum value is less than $\frac{k_{A}}{\rho_{A}}$, the transfer price rule is a binding constraint for all $R$. If this maximum value is greater than $\frac{k_{A}}{\rho_{A}}$, the transfer price rule is binding for large values of $R$, and possibly for low values of $R$, depending on the difference between $R_{B}$ and $\sigma$. Consideration of numerical examples shows that all cases can occur.

Large $\frac{k_{A}}{\rho_{A}} \quad$ The lower limit of the relevant range of $R$ is the same for the large$\frac{k_{A}}{\rho_{A}}$ and the small- $\frac{k_{A}}{\rho_{A}}$ cases. By subtraction, the upper limit of the range of $R$ for the large $\frac{k_{A}}{\rho_{A}}$ case is less than the upper limit of $R$ in the small $\frac{k_{A}}{\rho_{A}}$ case. Considering (64), the transfer pricing rule is binding for all admissible $R$ for the large $\frac{k_{A}}{\rho_{A}}$ case if

$$
\frac{1}{4} \frac{3+\sigma^{2}}{7+\sigma^{2}}-\frac{\sigma}{2\left(8+\sigma^{2}\right)} \frac{(R-\sigma)(2 R+\sigma)}{R}\left[\frac{1}{2}-\frac{3 \sigma}{\left(1-\sigma^{2}\right)\left(8+\sigma^{2}\right)}(R-\sigma)\right]>0 .
$$

Graphical analysis and evaluation of the left-hand-side of (68) for $0 \leq \sigma \leq 1$ and $0.25 \leq R \leq 2$ shows that this condition is always met. The transfer price rule is always a binding constraint for large $\frac{k_{A}}{\rho_{A}}$.

\section{References}

Bravo, Laura Ferrari and Paolo Siciliani "Exclusionary pricing and consumers harm: the European Commission's practice in the DSL market," Journal of Competition Law \& Economics 3(2), June 2007, pp. 243-279.

Carlton, Dennis W. "Should 'price squeeze' be a recognized form of anticompetitive conduct," Journal of Competition Law and Economics 4(2), June 2008, pp. 271-278.

Crocioni, P. and C. Veljanovski "Price squeezes, foreclosure and competition law: principles and guidelines," Journal of Network Industries 4, 2003, pp. 2860.

Hart, Oliver and Jean Tirole "Vertical integration and market foreclosure," Brookings Papers on Economic Activity: Microeconomics 1990, pp. 205-276.

Hovenkamp, Erik N. and Herbert Hovenkamp "The viability of antitrust price squeeze claims," Arizona Law Review 51(2), 2009, pp. 273-303.

Lafontaine, Francine and Margaret Slade "Exclusive contracts and vertical restraints: empirical evidence and public policy," September 2005 (also in Paolo Buccirossi, editor Handbook of Antitrust Economics. Cambridge, Massachusetts: MIT Press, 2008, pp. 391-414). 
Martin, Stephen "Microfoundations for the linear demand product differentiation model, with applications," Purdue University Economics Working Paper 1221, March 2009.

Motta, Massimo and Alexandre de Streel "Excessive pricing and price squeeze under EU law," in Claus-Dieter Ehlermann and Isabela Atanasiu European Competition Law Annual: 2003 What Is an Abuse of a Dominant Position?. Oxford and Portland, Oregon: Hart Publishing, 2006, pp. 92-125.

Posner, Richard A. Antitrust Law: An Economic Perspective. Chicago: The University of Chicago Press, second edition, 2001.

Sidak, J. Gregory "Abolishing the price squeeze as a theory of antitrust liability," Journal of Competition Law and Economics 4(2), June 2008, pp. 279309 . 